\title{
Tipos de Pastas Italianas
}

\author{
Types of Italian Pasta \\ Elsa Nathalie Barranco Angeles ${ }^{a}$
}

\begin{abstract}
:
Pasta is one of the staples of Italian cuisine and there is a great variety, there are different colors, sizes and shapes. Usually, pasta is always served accompanied by some sauce and always seasoned with spices such as oregano or basil. There are dried and fresh pasta and each one has a specific function within Italian Gastronomy, its cooking is simple but strict and detailed

Keywords:

Types of Italian pasta, sauces, shapes

Resumen:Haga clic o pulse aquí para escribir texto.

La pasta es uno de los alimentos básicos de la cocina italiana y existe una gran variedad, las hay de diferentes colores, tamaños y formas. Habitualmente, la pasta siempre se sirve acompañada de alguna salsa y siempre aderezada con especias como el orégano o la albahaca. Existen pastas secas y frescas y cada una tiene una función específica dentro de la Gastronomía italiana, su cocción es simple pero estricta y detallada
\end{abstract}

\section{Palabras Clave:}

Tipos de pasta italiana, salsas, formas

\section{Introducción}

Aunque la pasta es el alimento italiano por excelencia no fueron los italianos los inventores de este platillo. Cuenta la historia que fue Marco Polo el que introdujo la pasta en Italia en el siglo XIII, a bordo del barco Ya Won Ga Sin, al regresar de uno de sus viajes a China. Por lo tanto el verdadero origen de la pasta podría estar en China.

\section{Tipos de Pasta Italiana}

La variedad de tipos de pastas alimenticias es inmensa. La pasta fresca es aquella que, una vez elaborada, no se somete a un proceso de secado final, por lo que presenta una humedad del $30 \%$. Se comercializa recién elaborada y su periodo de conservación es breve.

También hay pastas enriquecidas a las que se les ha añadido algún ingrediente como gluten, soya, huevo, leche o verduras para aumentar su valor nutritivo. Algunos ingredientes proporcionan color, como el huevo (amarillo brillante), tomate (rojo) o espinacas (verde).
Además, Tambien se puede encontrar pasta rellena, a la que se le añadido un relleno o farsa que puede estar formado por carne, pescado, verduras, pan rallado, huevos o grasas. Entre los tipos de pasta rellena más conocidos se encuentran los canelones, tortellini, ravioli o rollitos de primavera.

Existen también dentro de esta clasificación, las pastas largas como el espaguetti, cabello de angel, fusilli y linguine. Dentro de la variedad de pastas con formas especiales se encuentran, Conghiglie, Gnocchi, Lumache, Orecchiette, Radiatori, Strozzapreti o Ruote di Carro.

\section{Nombre de la Práctica}

${ }^{a}$ L.G Elsa Nathalie Barranco Ángeles Profesor por Asignatura, Universidad Autónoma del Estado de Hidalgo, Instituto de Ciencias 


\section{Pasta al Pesto}

\section{Insumos Requeridos para su realización}

\begin{tabular}{|l|c|c|}
\hline Ingredientes & Cantidad & Unidad \\
\hline Albahaca & 0.050 & $\mathrm{~kg}$ \\
\hline Piñon & 0.050 & $\mathrm{~kg}$ \\
\hline $\begin{array}{l}\text { Queso } \\
\text { Parmesano }\end{array}$ & 0.050 & $\mathrm{~kg}$ \\
\hline Ajo & 0.010 & $\mathrm{~kg}$ \\
\hline Aceite de oliva & 0.020 & $\mathrm{lt}$ \\
\hline Pasta Fusilli & 0.005 & $\mathrm{~kg}$ \\
\hline
\end{tabular}

\section{Procedimiento}

1.- Blanquear las hojas de albahaca para evitar la oxidación.

2.- Para hacer la salsa, licuar la albahaca junto con el ajo, el queso parmesano, aceite de oliva y piñón.

3.-Mezclar hasta que sea una mezcla uniforme y fácil de manejar.

4.-Cocer la pasta al dente y mezclar inmediatamente con la salsa pesto

Utensilios

Licuadora, coludo, cuchara de servicio.

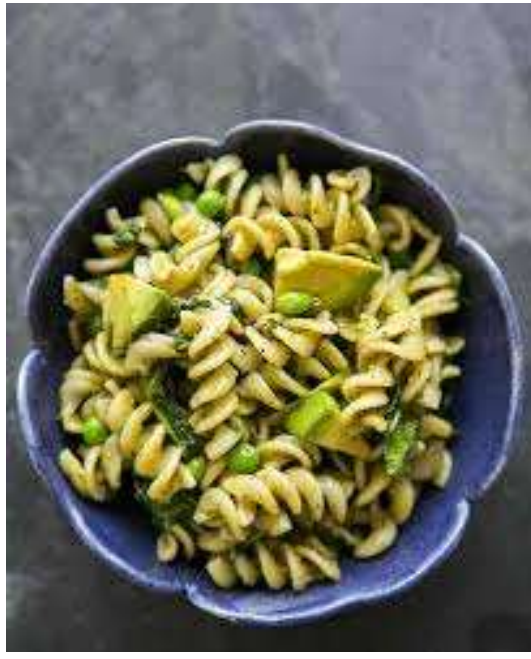

\section{Referencias}

[1] Bernasconi, C. (2010) El gran libro de la cocina italiana, Everest, España.

[2] Vv. Aa. (2016). Contemporary eataly Italian Cooking. Estados Unidos: Phaidon

[3] Piras, C. (2011) Culinaria italia, H.F. Ullman, España 